\title{
BULLS, BEARS, AND RETIREMENT BEHAVIOR
}

\author{
COURTNEY C. COILE and PHILLIP B. LEVINE*
}

\begin{abstract}
The authors examine the relationship between stock market performance and retirement behavior. They first present a descriptive analysis of the wealth holdings of older households and simulate the labor supply response among stockholders necessary to generate observed retirement patterns. Few households, they find, have substantial stock holdings, and these holdings would have to be extremely responsive to market fluctuations to explain observed labor force patterns. The authors then exploit stock market fluctuations since the early 1980s (particularly the boom and bust between 1995 and 2002), along with variation in stock exposure, to generate a double quasi-experiment, comparing the retirement and labor force re-entry patterns over time of those more and less exposed to the market. Any difference in behavior that emerged during the boom should have reversed itself during the bust. The authors find no evidence that changes in the stock market drove aggregate trends in labor supply.
\end{abstract}

A fter posting record gains in the late 1990 s, the U.S. stock market dropped precipitously starting in the year 2000 . In the twelve months following the market peak in March 2000, the benchmark S\&P 500 Index lost over one-quarter of its value and the NASDAQ Composite Index lost over $60 \%$ of its value; by October 2002 , the S\&P 500 had fallen by $50 \%$ from its peak and the NASDAQ had fallen by nearly $80 \%$.

This remarkable decline in stock value occurred at a time when more Americans were exposed to the stock market than ever before, often through participation in their pension plans. Friedberg and Webb (2003)

* Courtney Coile is Assistant Professor and Phillip Levine is William R. Kenan, Jr. Professor, both at Wellesley College. The authors thank Wellesley College for financial support and seminar participants at the National Bureau of Economic Research's Aging Workshop, UCLA Department of Economics, and the Board of Governors of the Federal Reserve System for helpful comments. reported that $79 \%$ of full-time workers with pensions had a $401(\mathrm{k})$ plan or other type of defined contribution plan in 1998, rising from $40 \%$ in 1983 . Poterba (2001) found that $52 \%$ of households held some stock in 1998, either through direct ownership of individual stocks or stock mutual funds or in their defined contribution plan or individual retirement account (IRA), up from $36 \%$ in 1989 . As a result, it was widely predicted that the stock market drop would force many older workers to postpone retirement. ${ }^{1}$

Aggregate labor force statistics appear to offer some support for this hypothesis. Eschtruth and Gemus (2002) noted that

The data and programs used to generate the results presented in this paper are available from the authors, for replication purposes, upon request. Contact the first author at ccoile@wellesley.edu.

${ }^{1}$ For instance, in response to plummeting stock prices, the July 29, 2002 cover of Time Magazine asked, "Will You Ever Be Able to Retire?"

Industrial and Labor Relations Review, Vol. 59, No. 3 (April 2006). (C) by Cornell University. $0019-7939 / 00 / 5903 \$ 01.00$ 
the two-percentage-point increase in labor force participation rate for older workers (aged 55 to 64) that occurred between early 2000 and early 2002 was unprecedented in the United States since World War II and was particularly noteworthy for having occurred during a recession, when labor force participation is typically flat or declining. They suggested that "plunging stock portfolios may have caused some older workers to postpone retirement and convinced some early retirees to rejoin the labor force."

However, there are reasons to be skeptical that the drop in the stock market had much of an impact on aggregate labor force behavior. First, if the bear market led people to delay retirement, one might have predicted that the bull market in the late 1990s would have led individuals to retire earlier. Yet data from the Bureau of Labor Statistics indicate that the labor force participation rate for individuals 55 to 64 actually rose by about 2 percentage points during the 1995 to 1999 boom years. ${ }^{2}$ Moreover, while considerably more workers have stock market holdings now than in the past, many workers may not yet have accumulated large balances in these accounts and thus may be unlikely to respond to even a sizeable drop in the market. While individual investors may have altered their retirement plans, the ability of stock fluctuations to drive aggregate labor force patterns may be limited.

In this paper, we examine the relationship between stock market performance and retirement behavior over the past two decades, paying particular attention to the boom and bust periods of 1995-1999 and 2000-2002, respectively. For our analysis, we use data from the first six waves (19922002) of the Health and Retirement Study (HRS), from the March 1981 to 2003 Cur-

\footnotetext{
${ }^{2}$ These data were accessed from the Bureau's customized table-maker, available at data.bls.gov and accessed on July 5, 2004. Although this pattern may be partly attributable to the robust economy during the period, our own calculations (described below) show that even cyclically adjusted annual retirement rates were unaffected by the boom.
}

rent Population Surveys (CPS), and from the 1992, 1995, and 1998 Surveys of Consumer Finances (SCF). We first provide a descriptive analysis that begins by documenting trends in retirement patterns using the CPS and HRS data. We also present descriptive statistics detailing the stock market holdings of older households in the late 1990 s and then provide a "back-of-theenvelope" calculation to simulate the magnitude of the response to the recent stock market decline that would be required to generate the observed drop in retirement rates. Second, we undertake a reducedform analysis to compare the effect of the stock market on the retirement behavior of individuals who are likely to have been differentially affected by changes in the market, such as persons with and without defined contribution pension plans. Evidence supporting an impact of the stock market on retirement behavior would require that those who are more likely to own stock are also more likely to retire in booms and less like to retire in busts. We also apply the same empirical strategy to an analysis of labor force re-entry decisions.

This paper makes two important contributions to the existing literature on the stock market and retirement. First, along with Kezdi and Sevak (2004), we are the first to look at both the boom period of the late 1990s and the bust period that followed. But our methodology more directly imbeds these two periods into a quasi-experimental framework, taking advantage of what amounts to a double experiment in which differences across groups that are predicted to emerge during the boom are also predicted to reverse during the bust. Second, we focus on the aggregate response to market movements rather than estimate individual wealth effects. Our goal is to estimate the relationship between market fluctuations and aggregate changes in retirement rather than the relationship between wealth and retirement.

\section{Literature Review}

Economic theory suggests that the consumption of leisure, like the consumption 
of other normal goods and services, should increase when the household experiences a positive wealth shock and, conversely, decrease when the household experiences a negative wealth shock. For households nearing retirement age, a positive (negative) wealth shock may lead family members to retire earlier (later), especially if workers lack the flexibility to change the number of hours they work at their current job. Dramatic changes in stock market returns may generate shocks of this nature. Therefore, the broader literature on wealth shocks as well as those studies directly examining the role of stock market fluctuations can inform this study.

Recent research examining the role of wealth shocks more broadly has relied on sources of variation in retirement wealth that are exogenous to an individual's preferences for leisure. Holtz-Eakin et al. (1993) and Joulfaian and Wilhelm (1994) used inheritances, Imbens et al. (2001) considered lottery winnings, and Krueger and Pischke (1992) took advantage of Social Security changes. Overall, this literature finds mixed support for the role of wealth shocks on retirement.

A second related strand of the literature explores the impact on retirement decisions of unexpected changes in wealth associated with stock market fluctuations, such as the boom of the late 1990s. Coronado and Perozek (2003) and Sevak (2001) both found a relationship between unexpected capital gains and retirement. But differences in unexpected gains are strongly (if not perfectly) correlated with previous differences in the amount of stock ownership. These differences may be correlated with other unobservable characteristics, like individuals' preferences for leisure or their ability to plan for retirement.

A third set of analyses has introduced quasi-experimental methods, examining whether retirement behavior responds differently to market variation among those with more and less exposure to the stock market. ${ }^{3}$ Sevak (2001) found that men in

${ }^{3}$ Hurd and Reti (2001) and Hurd et al. (2005) used similar methods to examine the impact of market defined contribution (DC) pension plans increased their retirement rates by more than men in defined benefit (DB) pensions when the stock market was rising. Similarly, Kezdi and Sevak (2004) found that retirement rates were lower for older workers with dividend income (a proxy for stock market exposure) than for other workers in 2001 and 2002, when the market was falling, though their retirement rates were also lower during the late 1990s, when the market was rising. These studies are limited by sometimes poor measures of stock market exposure and an inability to capture on-going differences in trends between groups. Overall, the evidence for greater labor supply responses to changes in the stock market for those with more exposure to the market is far from conclusive. ${ }^{4}$

\section{Data and Empirical Strategy}

We use three different sources of data, each of which has distinct strengths and weaknesses that make it better suited for certain parts of the analysis. Where possible, each analysis is replicated using a second data source to confirm the results.

The first data set is the Health and Retirement Study (HRS). The HRS began in 1992 as a longitudinal study of persons born between 1931 and 1941 and their spouses, with re-interviews of these 7,500

fluctuations on the subjective probability of retirement after age 62. They found no evidence that market fluctuations were more closely related to subjective retirement probabilities for those who faced greater stock market exposure.

${ }^{4}$ Other studies have also examined stock market fluctuations and retirement behavior using an approach whereby relevant elasticities are either taken from other studies or estimated within the framework of a structural retirement model and then used to predict responses to market fluctuations (Cheng and French 2003; Gustman and Steinmeier 2002). The labor supply responses to the stock market boom and bust estimated in these papers are quite large, on the order of 2 to 3 percentage points. However, the methodological approaches employed in these papers are sufficiently distinct from the one we apply in our analysis that we do not discuss them in further detail here. 
households every two years; in 1998, additional birth cohorts were added to the survey so that it now includes persons born in all years through 1947 . The HRS contains richly detailed information on demographics, labor supply, finances, and health. The principal advantage of the HRS is that it provides comprehensive data for a sample of near-retirement-age households and follows them over time.

In this paper, we use two main components of the HRS: information on retirement behavior and on wealth holdings. For our analysis of retirement behavior, we use longitudinal data on wave 1 (1992) respondents for the first six waves of the survey (1992-2002). In one part of that analysis, respondents contribute person-year observations for all years between 1992 and 2001 in which they were aged 55 to 70 , were working at the beginning of the calendar year, and had not previously retired; retirement is defined as reporting a labor force status of retired or disabled by the end of the calendar year. ${ }^{5}$ In a second part of that analysis, we construct an analogous sample of person-month observations, making use of the availability of data on month of retirement. We also present a descriptive analysis of household wealth holdings; we use wave 4 (1998) data for that analysis, because wave 4 is the last interview available prior to the stock market crash. ${ }^{6}$ In both the descriptive and retirement analy-

\footnotetext{
${ }^{5}$ The sample is constructed using HRS respondents who were working at wave 1 , so respondents who retired in 1992 prior to their interview are not in the sample. Persons who exited the labor force by other pathways (for example, exited to homemaker status, exited to other or no labor force status, or left the survey) did not provide a retirement date and thus are used in the sample only for the years in which it is known they worked the full year, and are omitted thereafter. Results are very similar if exits to disability are treated in the same manner. If persons reported multiple labor force status codes at one point in time, the following hierarchy is used: working, retired, disabled, all other.

${ }^{6} \mathrm{We}$ acknowledge that the values of these holdings immediately prior to the bust would likely be somewhat higher due to continued growth in the market through March 2000.
}

ses, several variables are used to proxy for likely exposure to the stock market: educational attainment, ownership of a DC plan or IRA within the household, and ownership of individual stocks or stock-based mutual funds. ${ }^{7}$ A designation of having "high value" DC and IRA or stock balances refers to having balances in excess of $\$ 50,000$ in 2003 dollars.

The Current Population Survey (CPS) is a monthly survey of approximately 50,000 households and forms the basis for most published U.S. labor statistics; we use data from annual March CPS surveys from 1981 to 2003, referencing behavior in 1980 through 2002. The CPS includes about the same number of older households as the HRS, but it collects less information on them and does not follow the same households over time. CPS data, however, are available for a longer period of time, allowing us to observe greater cyclical variability in the stock market to compare to retirement behavior. ${ }^{8}$ The March surveys provide not only current labor market activity, but also retrospective reports from the past calendar year. From these data, we define a transition into retirement as occurring when an individual reports working at least

\footnotetext{
${ }^{7}$ IRA and stock ownership status and asset values come from the RAND HRS data file, which imputes missing values using bracketed data (constructed based on questions such as whether respondents' accounts amounted to more or less than $\$ 10,000$ ) and other information. Because asset allocation of DC balances is observed for only a small fraction of DC plans, DC plan participation is used as a proxy for stock market wealth in the analysis, though of course not all participants will invest their DC balances in stock. In the regression analysis, asset ownership is determined based on ownership at wave 1 , so as to be exogenous to the subsequent boom and bust in the stock market. In the descriptive analysis, asset ownership is based on ownership at wave 4 , as the point of the exercise is to describe assets in the pre-crash period.

${ }^{8}$ We also experimented with just using data from the 1990s onward to examine the sensitivity to changes in labor and financial markets. The results from this exercise were qualitatively similar to those reported here, but somewhat less precise, as one would expect with fewer observations.
} 
13 weeks in the preceding calendar year, but he or she is currently out of the labor force on the survey date..$^{9}$ Although data on the wealth holdings of CPS respondents are limited, we are able to use some information on whether or not the individual was included in a pension plan (defined benefit or defined contribution) and on that person's educational attainment to provide a rough proxy for stock holdings.

The Survey of Consumer Finances (SCF) is a survey of about 4,500 households conducted every three years to collect detailed data on the finances of U.S. households. Compared to the HRS, the SCF has more in-depth information on stock holdings. It provides no information that would enable us to detect retirement transitions, however, so these data can only contribute to our descriptive analysis of wealth holdings. In the analysis, data from the 1992, 1995, and $1998 \mathrm{SCF}$ are pooled to generate sample sizes large enough to estimate descriptive statistics on the wealth holdings of older households and of subgroups of this population.

Our empirical analysis of the link between the stock market and retirement is divided into two parts: a descriptive analysis and a reduced-form analysis. The goal of the descriptive analysis is to explore the plausibility of a large labor supply response to the recent drop in the stock market. First, we present detailed statistics on the wealth holdings of older households in the late 1990 s to examine the level of stock market exposure in this population. Second, we perform a "back-of-the-envelope" calculation to estimate the magnitude of the response to the stock market shock that would be necessary to explain the drop in the average retirement rate; this exercise is described in more detail below.

In the reduced-form analysis, the empirical strategy is to compare the response to changes in the stock market among indi-

\footnotetext{
${ }^{9}$ Assuming those 13 weeks worked last year all took place in the first quarter, this definition is comparable to an annual window in which retirements are observed between March of one year and of the next.
}

viduals likely to have been differentially affected by such changes. The identification of stock market effects relies on quasiexperimental variation in exposure to the stock market, which comes from factors such as education level, participation in a defined contribution pension plan or IRA, and ownership of stocks or stock mutual funds. We hypothesize that if the stock market affects people's retirement behavior, then the response to changes in the stock market should be larger among groups with greater exposure to the stock market. Importantly, any differential in retirement behavior across groups generated during the boom should be reversed during the bust. Findings to that effect in response to this double experiment would provide strong evidence of a causal effect of stock market fluctuations.

Specifically, we estimate regressions of the form

$$
\begin{gathered}
\operatorname{RETIRE}_{i s t}=\beta_{0}+\beta_{1} \text { BuST }_{t}+ \\
\beta_{2} \text { BoOM }_{t}+\beta_{3} X_{i s t}+\gamma_{s}+\varepsilon_{i s t},
\end{gathered}
$$

where RETIRE is a dummy variable for whether individual $i$ residing in state/region $s$ who worked in year $t-1$ retires in year $t$, Bust and Воом are dummy variables for whether the person-year observation occurs in a bust year (2000-2001 in the HRS or 2000-2002 in the CPS) or a boom year (1995-99), and $X$ is a set of demographic characteristics including exact age dummy variables, race and ethnicity, gender, marital status, the unemployment rate (state-level in the CPS or region-level in the HRS), and state or regional fixed effects $\left(\gamma_{s}\right)$. The sample is restricted to individuals working in year $t-1$ and, in the HRS, to those workers who have not retired previously. Therefore, this model is very similar to a discrete time proportional hazard

\footnotetext{
${ }^{10}$ Estimating models like equation (1) using a logit specification is equivalent to estimating a discrete time proportional hazard model (Allison 1984). We opt to estimate equation (1) as a linear probability model for ease of interpretation of the coefficients; the results using a logit specification are qualitatively similar.
} 
model. ${ }^{10}$ This model is estimated first for all workers aged 55-70. But the true test of the impact of market fluctuations comes by estimating this model separately for groups who may be differentially affected by changes in the stock market and comparing coefficients for the boom and bust periods across groups. ${ }^{11}$

Estimation of equation (1) provides a way to identify whether there is a relationship between the stock market and retirement, but does not determine the magnitude of the impact of market fluctuations on retirement behavior. To do so, we estimate a second set of regressions of the form

$$
\begin{gathered}
\operatorname{RETIRE}_{i s t}=\beta_{0}+\beta_{1} \Delta S \mathcal{E}^{2} P 500+ \\
\beta_{2} X_{i s t}+\gamma_{s}+\varepsilon_{i s t},
\end{gathered}
$$

where $\Delta S \mathcal{E} P P 500$ is the percentage change in the S\&P 500 Index over the previous twelve months. As before, the model is estimated for all workers and separately for groups of workers likely to have been differentially affected by changes in the stock market. Note that the identification strategy is similar to that underlying equation (1), but this analysis allows for the effect to be parameterized.

Finally, we explore the effect of stock market fluctuations on the decision to reenter the labor force following retirement, as this may also constitute an important labor supply response to changes in the market. Specifically, we re-estimate equations (1) and (2) using labor force re-entry as the dependent variable. In the CPS, labor force re-entry is defined as working on the survey date conditional on having worked fewer than 13 weeks in the previous year. In the HRS, labor force re-entry is defined as working at the current wave of the survey conditional on having been out of the labor force at the last wave. ${ }^{12} \mathrm{We}$ hypothesize that if the market affects re-

\footnotetext{
${ }^{11}$ We choose to estimate the model separately by group rather than interact the group dummy variable with the boom and bust dummies in order to allow the other covariates, notably the age dummies, to differ by group.

${ }^{12}$ The HRS labor force re-entry analysis is based on a sample of person-wave observations. Creating a
}

entry decisions, then those with greater exposure to the market will be relatively less likely to re-enter the labor force during the boom period and relatively more likely to do so during the bust period.

\section{Descriptive Analysis}

We begin our analysis by offering data from the CPS and HRS in Figure 1, which tracks changes in retirement patterns over time for workers ages 60-65. Since the size of an age cohort changes over time and since the economy moved from a substantial expansion in the late 1990 s to a period of recession and weak growth in the beginning of the current decade, we use the available data to generate retirement rates adjusted for age composition and business cycle conditions over time. ${ }^{13}$ Results from both surveys are consistent with the statistics reported in Eschtruth and Gemus (2002) in showing that retirement rates took a noticeable and statistically significant drop exactly in 2000, which corresponds with the plunge in the stock market. ${ }^{14}$ In both datasets, despite the differ-

person-year sample for this analysis is not feasible, because the date of labor force re-entry is either missing or inconsistent (for example, the respondent reports starting the current job in 1995 but previously reported being out of the labor force in 1996) for about half of all re-entrants. In this analysis, the boom period includes labor force transitions between waves 3 and 4 and waves 4 and 5 (1996-1998, 19982000) and the bust period includes transitions between waves 5 and 6 (2000-2002).

${ }^{13}$ These estimates are obtained from regression models of the "retirement rate" (whose definition differs in the two surveys) on state-level (in the CPS) and region-level (in the HRS) unemployment rates, exact age dummies, and year fixed effects (and no constant); reported results reflect the year fixed effects assuming a $5 \%$ unemployment rate and an equal share of workers ages 60-65. In the CPS, year labels are associated with the survey conducted in March of the following year, since most of the retirement that is captured in that survey is likely to reflect behavior that occurred last year, as described above. All HRS figures begin in 1993, as the sample is constructed using wave 1 workers (see above) and does not capture all retirements in 1992.

${ }^{14}$ Alternatively, the drop in retirement rates in 2000 could have been merely the realization of a longer-term decline in retirement among older work- 
Figure 1. Adjusted Retirement Rates for Workers 60 to 65.

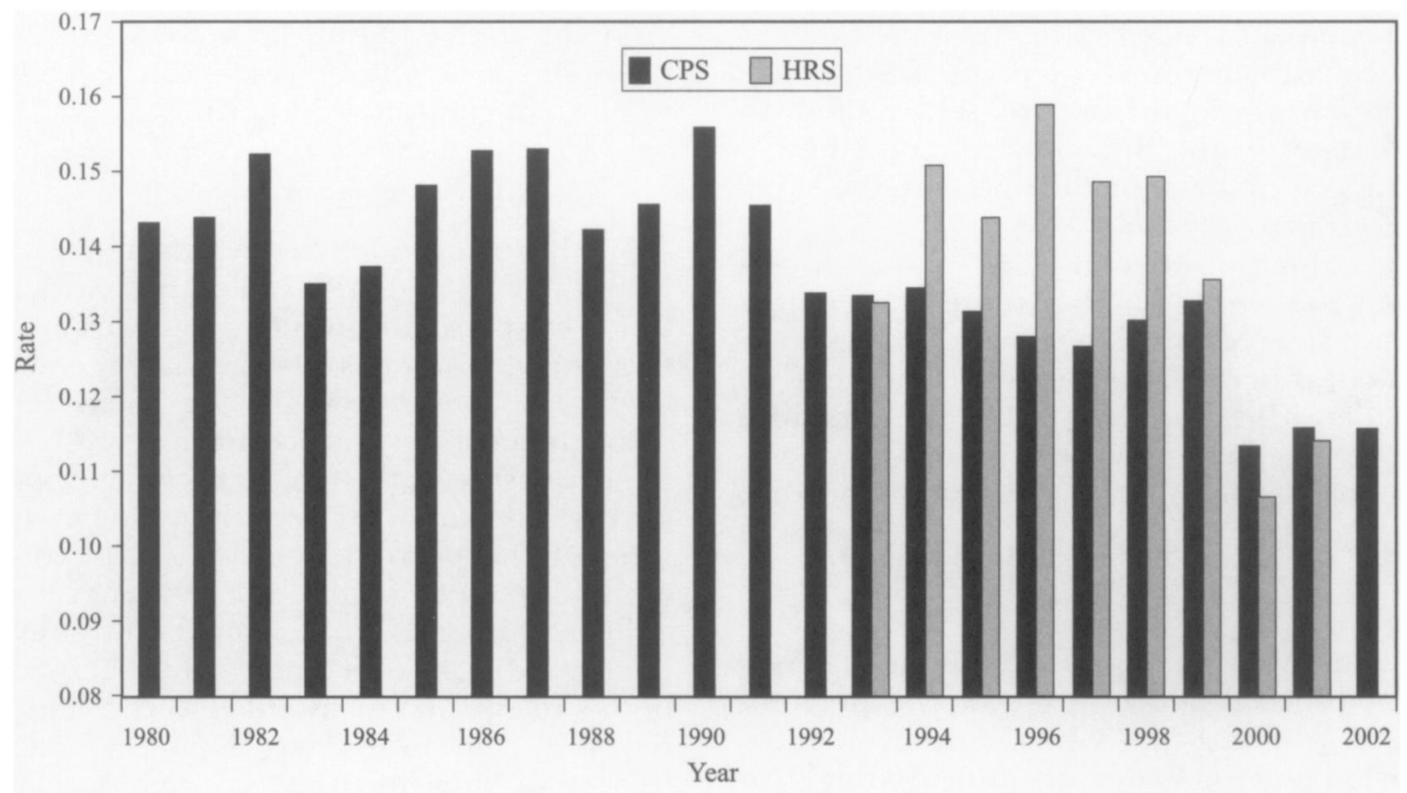

Note: Definitions of retirement are not consistent between CPS and HRS (see text for details). Rates reflect retirement behavior adjusted for variation in the unemployment rate and the exact age composition of 60-to-65 year-olds. The estimates assume an unemployment rate of $5 \%$ and are measured at the average retirement hazard between age 60 and 65 . In the CPS, year $t$ reflects retirements that take place roughly between March of year $t$ and March of year $t+1$.

ences in the definition of retirement transitions, older workers appear to have reduced their likelihood of retiring by about two percentage points during the market bust.

As previewed earlier, however, there are reasons to be skeptical of a causal relationship between recent market performance and retirement even based on this preliminary analysis. First, the change in the retirement rate in 2000 is quite large, especially considering the timing of the market decline. Although the S\&P 500 peaked for

ers (see Burtless and Quinn 2002). A second possibility is that changes in Social Security rules, including the increase in the Normal Retirement Age for workers reaching age 62 in the year 2000 or later and the elimination of the earnings test for workers age 65 and above starting in 2000 , affected retirement behavior. the year on March 24 at 1,527 and declined to 1,320 by the end of the year (a $14 \%$ decline), on September 1, the value stood at 1,521 . This means that there should have been little or no retirement response in the first three quarters of that year. Although the argument is not quite as strong with the NASDAQ, which hit its annual peak of 5,049 on March 10 and fell to 2,471 by the end of the year (a $51 \%$ decline), the market's index stood at 4,234 as late as September 1 . This also suggests that much of the response had to take place late in the year and must have represented a very large change in behavior over a very short period of time.

Second, the CPS data provide little evidence of a symmetric response to the booming stock market of the late 1990s. Cyclically adjusted retirement rates between 1995 and 1999 were actually lower over that period than they had been previously despite the greater wealth generated by exceptional 
stock market returns. However, other timevarying factors may confound this simple analysis of the effect of the stock market on retirement, so this evidence, while informative, is far from conclusive.

The fact that most older households have only limited stock holdings also suggests that market fluctuations may not have a sizeable effect on aggregate labor market behavior..$^{15}$ The nature of these holdings is reported in Tables 1A and 1B, using data from the HRS and SCF, respectively. Statistics reflect the holdings of workers nearing retirement age (55 to 60). Data from the 1998 HRS and from the 1992, 1995, and 1998 SCF are employed to assess holdings prior to the stock market plunge in early $2000 .{ }^{16}$

In the HRS (Table 1A), over two-thirds of older households had retirement accounts at the time of the survey- $46 \%$ of households had one or more members with a defined contribution (DC) pension plan, $47 \%$ of households had an IRA, and $68 \%$ of households had one or both types of retirement account. Yet it is important to keep in mind that these accounts were not necessarily invested entirely, or even mainly, in stocks; older households making more conservative investments based on their age may have reduced their holdings in stockbased investments because of their riskier nature. Ownership of individual stocks or stock mutual funds outside of retirement accounts was less prevalent but still considerable, with $38 \%$ of households owning these assets. Overall, $75 \%$ of families had some type of account (DC pension, IRA, or stocks) that may have included stock hold-

\footnotetext{
${ }^{15}$ Engen et al. (2004) made a similar point regarding the impact of stock market fluctuations on the adequacy of retirement savings, stating that "because most stocks are held by households with substantial wealth, and most households hold very little equity, fluctuations in stock market values ... have little effect on households' ability to save adequately for retirement."

${ }^{16}$ We have also relaxed the sample restrictions placed on the analysis performed here and verified that we can replicate official SCF results on wealth holdings, published in Kennickel et al. (2000).
}

ings, although this statistic is also likely to overstate exposure to the stock market.

Median assets values in these accounts were high by historical standards, but still low relative to family income. Among households holding each type of asset, median holdings in DC accounts and IRAs were about $\$ 40,000$ each, while median stock holdings were $\$ 33,900$. Among households with any of these three accounts, median combined holdings were $\$ 68,900$. This represents less than one and a half times the median income, which was $\$ 48,728$ (in 2003 dollars) for households aged 55 to 64 in 1998 (U.S. Census Bureau 1999).

Moving across Table 1A, it is evident that the distribution of these assets was highly skewed. While $68 \%$ of families owned a DC plan or IRA, only $28 \%$ of families had combined balances of over $\$ 50,000$ in these assets, and median combined holdings for this subset of families were $\$ 208,800$. Similarly, only $17 \%$ of families had holdings of stocks in excess of $\$ 50,000$; median combined holdings for these families were $\$ 311,600$. Asset holdings also varied greatly by education level- $89 \%$ of college-educated households had some type of account that may have included stocks, but only $52 \%$ of high school dropout households did. The median combined holdings were $\$ 146,700$ for college-educated households compared to $\$ 20,300$ for high school dropout households. These differences in stock holdings are an important component of our quasi-experimental methodology.

Table 1B replicates these statistics using the SCF. The SCF statistics are broadly similar to those in Table 1A, though ownership of DC pensions and stocks is less prevalent and asset values are somewhat lower, as one would expect given the pooling of data with earlier years. Yet the SCF data have the advantage of including better information on whether DC pension and IRA assets were invested in stock. Figure 2 illustrates that the fraction of households reporting that their DC plan or IRA was invested mostly in stocks was consistently less than $50 \%$. This was also true for IRA plans as reported in the HRS. When DC pension and IRA assets are counted only if invested 


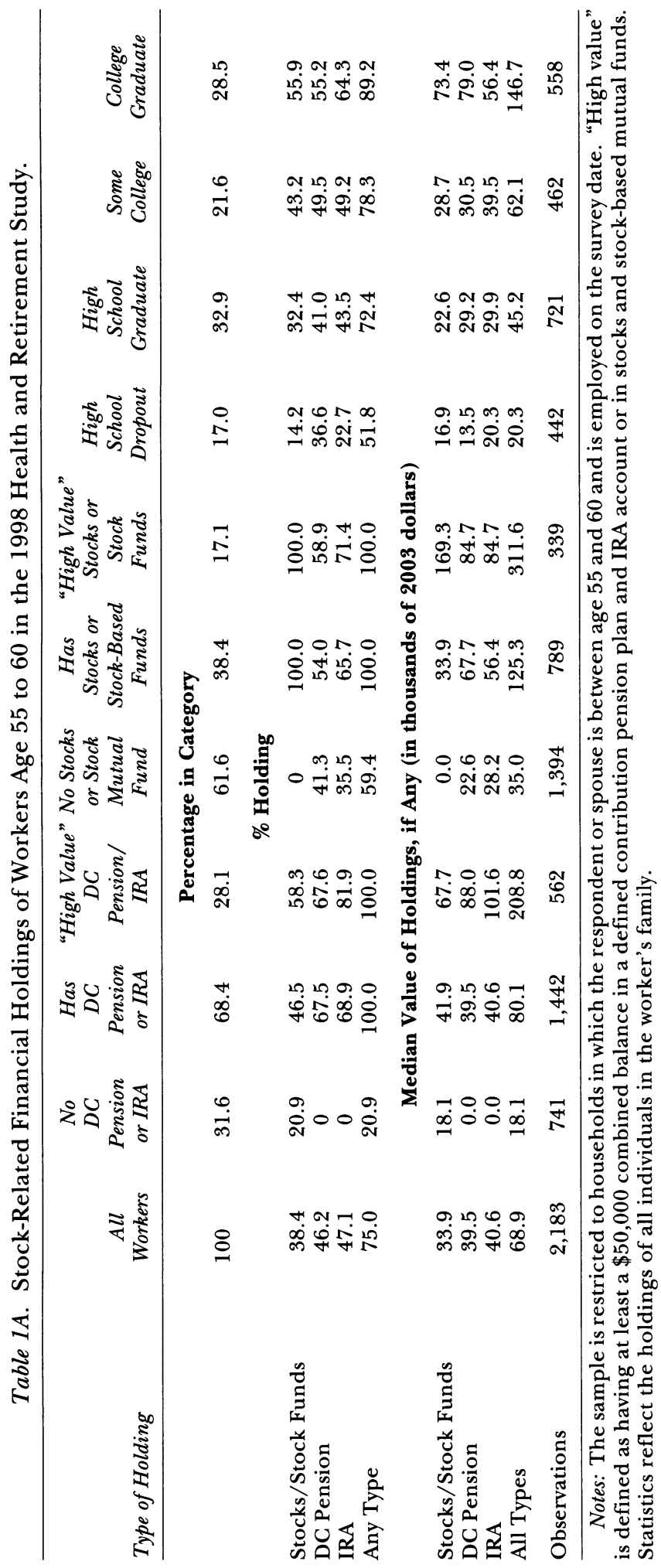




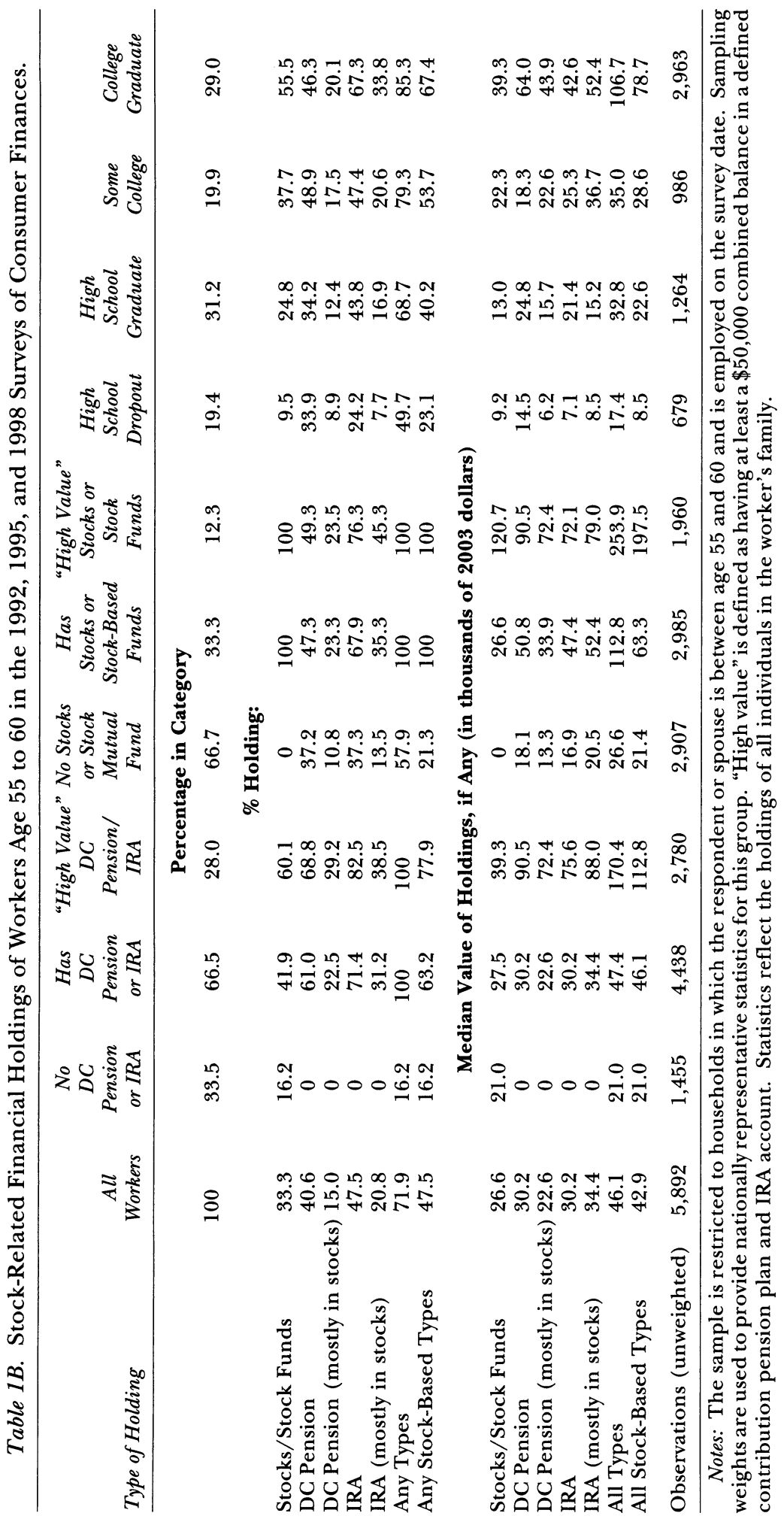


Figure 2. Investment Allocation in IRAs and Defined Contribution Pensions.

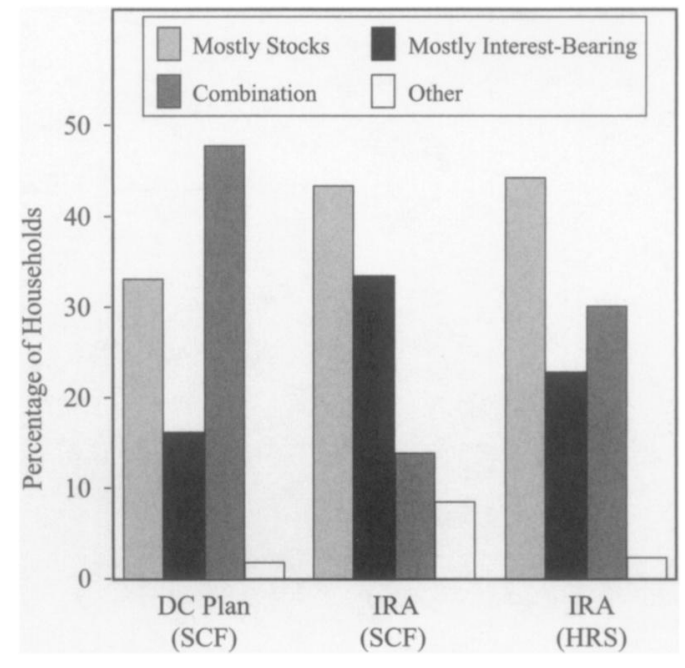

mostly in stock, both the fraction of households holding each type of asset and the median value of assets decrease significantly. While $41 \%$ of households had DC pensions, only $15 \%$ had pensions invested mostly in stocks; for IRAs, the equivalent figures are $48 \%$ and $21 \%$, respectively. Overall, only $48 \%$ of households had any assets invested mostly in stock, and the median value of such assets among these households was $\$ 42,900$, which is less than the 1998 median household income for this age group (in 2003 dollars).

The key point from these descriptive statistics is that the labor supply response to the drop in the stock market in 2000 is unlikely to have come from the median person. Fewer than half of older households had any assets invested mostly or wholly in stock, and median asset holdings for households that did were on the order of one year of household income. It seems unlikely that even a sizeable decrease in the value of these assets would have generated a large labor supply response.

To explore this point further, we conduct a "back-of-the-envelope" calculation to estimate the magnitude of the response to the 2000 stock market shock that would be necessary to explain the observed drop in the average retirement rate; the results of this analysis are shown in Table 2. We first restrict the sample of HRS respondents to those who were aged 55 to 70 and working at the beginning of 2000 . Then we categorize these workers according to the value of their stock assets at that time, where the categories include those with any assets and (among workers with assets) those with at least $\$ 25,000, \$ 50,000, \$ 100,000$, and $\$ 250,000$ in stock assets. Where assumptions are required to value stocks, we do so in a way that is likely to overvalue them. ${ }^{17}$ Finally, we calculate the monthly annuitized value of the loss incurred in a portfolio of each of these amounts as a result of the stock market drop during 2000. For example, a portfolio invested $70 \%$ in the S\&P 500 Index and $30 \%$ in the NASDAQ (the approximate relative market capitalization of the two indices at the end of 1999) would have dropped $25 \%$ between the market peak in March 2000 and the end of the year, resulting in a $\$ 6,250$ loss on a $\$ 25,000$ portfolio; this is equivalent to a $\$ 41$ decrease in monthly income if annuitized at a $5 \%$ real interest rate over 20 years. ${ }^{18}$

\footnotetext{
${ }^{17}$ The HRS has information on how IRAs are invested ("mostly in stock, mostly in interest-earning assets, or about evenly split") but collects such information for only a minority of DC plans, so this information was not used in Table 1A. Here, we assume that "invested mostly in stock" means $100 \%$ in stock, "mostly in interest-earning assets" means $1 / 3$ in stock, and "evenly split" means $2 / 3$ in stock. For people with missing DC or IRA asset allocation, we assign the mean stock percentage in this asset class for their education group. For a small number of people with missing DC asset values, we assign the median value for their education group. Asset values are those reported in the $1998 \mathrm{HRS}$, increased to the year 2000 level using the asset returns between the wave 4 interview date and March 2000 for a portfolio of which $70 \%$ is invested in the S\&P 500 and $30 \%$ in the NASDAQ; values are then adjusted to 2003 dollars using the CPI.

${ }^{18}$ As one way to benchmark the magnitude of such a drop in assets, we note that Coile et al. (2002) estimated that a typical one-earner couple forgoes $\$ 8,160$ (in 2003 dollars) in Social Security wealth by claiming at age 62 rather than at the optimal age of 65; although the authors estimated that delaying benefit claims would produce substantial benefits in
} 
Table 2. Simulated Retirement Rates for Those Aged 55 to 70

Holding Stocks Required to Match Observed Retirement Rates.

Stock Assets at Beginning

of 2000 (in 2003 dollars) $\geq X^{\mathrm{a}}$

Description

$X=0$

$25 K$

$50 K$

$100 \mathrm{~K}$

$250 K$

1) Monthly annuitized value of loss associated with stock market decline in 2000 at $\mathrm{X}^{\mathrm{b}}$

3) Percentage of HRS sample with stock assets $<X$

4) Predicted 2000 retirement rate for those with stock assets $<\mathrm{X}^{\mathrm{c}}$

5) Predicted 2000 retirement rate for those with stock assets $\geq \mathrm{X}$ and no response to stock market decline $^{c}$

6) Simulated retirement rate for those with stock assets $\geq X{ }^{d}$
$\$ 0$

67.8

32.3

4

$\$ 41$

$\$ 82$

$\$ 164$

$\$ 409$

48.8

39.5

31.0

18.2

51.2

60.5

69.0

81.8

12.3

12.3

12.1

12.2

12.8

12.4

12.4

12.4

12.4

7.0

3.6

1.1

$-6.5$

${ }^{\text {a}}$ Each column of this table represents the characteristics of the sample whose stock market values at the beginning of 2000 are above or below the defined level. See footnotes in text for greater detail regarding the construction of these values.

${ }^{\mathrm{b}}$ The 2000 market decline is calculated as a weighted average of the decline in the S\&P 500 (70\% weight) and the NASDAQ ( $30 \%$ weight), where the weights are determined according to the relative market values of the two indices at the end of 1999 .

'Predicted retirement rates represent the rates that would have been expected based on labor market conditions and the demographic characteristics (age, race/ethnicity, gender, region, and marital status) of the sample of respondents still working at the beginning of 2000. These predictions are obtained from regression models of retirement behavior using 1992-1999 HRS data.

${ }^{\mathrm{d}}$ Those with stock market assets below the lower bound are assumed to be unaffected by the market decline. The simulated retirement rate for those with stock assets at or above the cut-off is calculated to be the value necessary for the weighted average of the predicted rate for those below the cut-off and the simulated rate for those above the cut-off to match the aggregate rate observed in the 2000 HRS of $8.9 \%$.

We use these values to help determine which individuals would likely have responded to the stock market crash. Clearly, workers with no stock assets should not have responded, since they lost nothing. Workers under the $\$ 25,000$ cutoff were also unlikely to respond, as they faced a maximum annuitized loss of just $\$ 41$ per month. Using this logic, it seems reasonable that workers with stock assets up to perhaps $\$ 100,000$ (and even beyond) may not have

a wide variety of cases, they found that very few workers delayed. One possible explanation is that people are overly sensitive to seeing "cash on the table"; if this is the case, then it is possible that workers would respond to even relatively small decreases in stock assets. responded, as they faced an annuitized loss of no more than $\$ 164$ per month. ${ }^{19}$

Next, we estimate a retirement regression model using 1992-99 HRS data and use it to predict retirement probabilities in the year 2000 if the stock market was unchanged. ${ }^{20}$ Finally, using these predicted

\footnotetext{
${ }^{19}$ In 2002, mean annual expenditures for households headed by an individual between ages 65 and 74 were $\$ 32,243$, or $\$ 2,687$ per month (U.S. Department of Labor 2004). For such a household, $\$ 164$ would represent about $6 \%$ of spending. This percentage would likely be somewhat higher for the median household, but median consumption statistics are not provided in this report.

${ }^{20}$ The regression includes the unemployment rate and various demographic characteristics (age dummies, race/ethnicity, gender, region, and marital status).
} 
Figure 3. Adjusted Retirement Rates for Workers 60 to 65 in the Health and Retirement Survey, by Defined Contribution Pension/IRA Status.

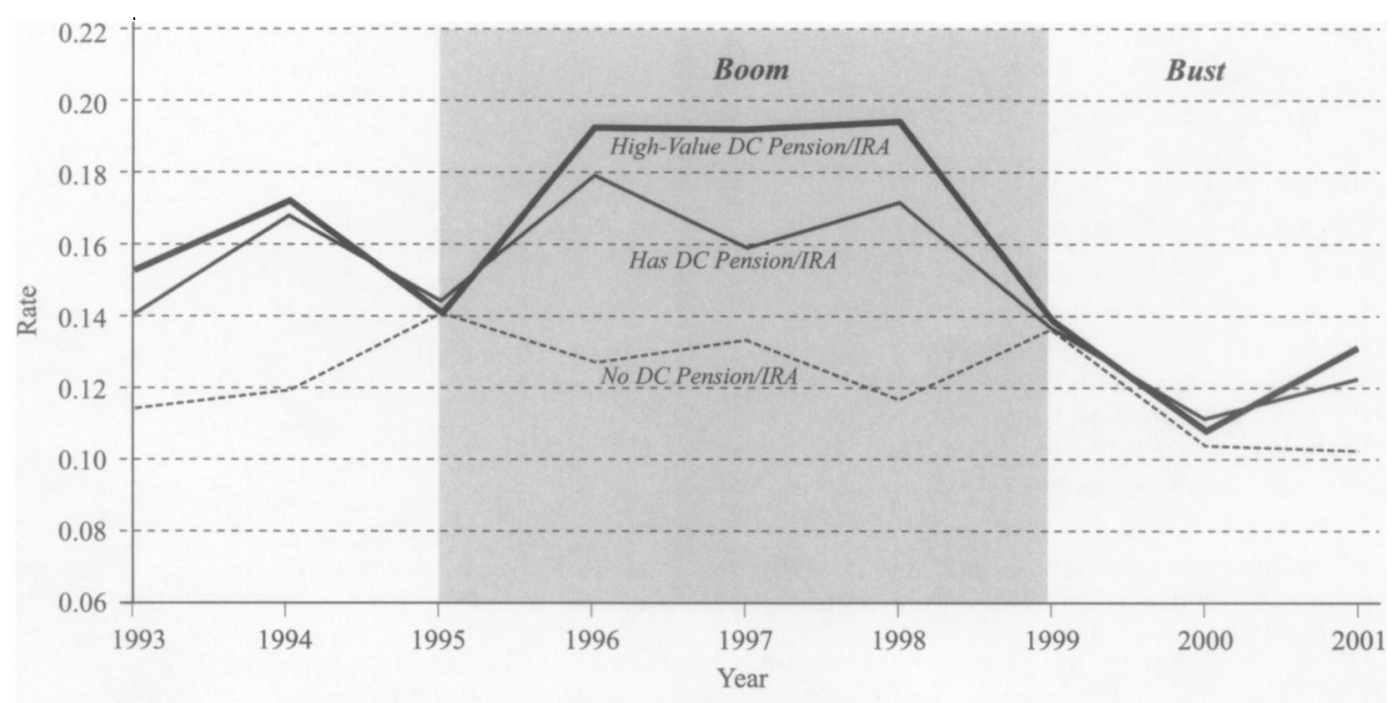

Notes: Rates reflect retirement behavior adjusted for variation in the unemployment rate and the exact age composition of 60 to 65 year olds. The estimates assume an unemployment rate of $5 \%$ and are measured at the average retirement hazard between age 60 and 65 .

probabilities for the households below each asset cutoff point, we calculate what the average retirement rate would have to have been among those above the cutoff in order to generate a weighted average retirement rate matching that actually observed in the sample in the year $2000,8.9 \% .^{21}$ For the most conservative assumption that only those without stocks failed to respond to the market crash, we estimate that the average retirement rate in the rest of the sample would have needed to drop from the predicted level of $12.8 \%$ to $7.0 \%$. Under the alternative assumption that individuals in households with up to $\$ 25,000, \$ 50,000$, or even $\$ 100,000$ would not have responded, the required retirement rate among those above the cutoff falls to $5.3 \%, 3.6 \%$, and

\footnotetext{
${ }^{21}$ Note that this statistic is smaller than that displayed in Figure 1, largely because the sample used here includes workers 55 to 70 compared to a sample of those 60 to 65 in Figure 1.
}

$1.1 \%$, respectively. Using the $\$ 100,000$ cutoff, it would need to have been the case that virtually no one with more than $\$ 100,000$ in stock assets retired during the year 2000 for the observed drop in the retirement rate to be due to the stock market crash, which seems highly implausible. The superficial plausibility falls even more when one recognizes that the change in retirement behavior was unlikely to have begun until later in 2000 based on the monthly movements in market indices, as described earlier. If the asset cut-off is defined to be $\$ 250,000$, it is actually impossible to simulate the observed behavior. Overall, this simulation shows that the response to the 2000 stock market decline had to have been extremely strong (and possibly implausible or even impossible) to explain the observed drop-off in retirement rates. ${ }^{22}$

\footnotetext{
${ }^{22}$ Alternatively, it is possible that workers with relatively little stock market wealth were "irrationally
} 
Figure 4. Adjusted Retirement Rates for Workers 60 to 65 in the Health and Retirement Survey, by Stock Holdings Status.

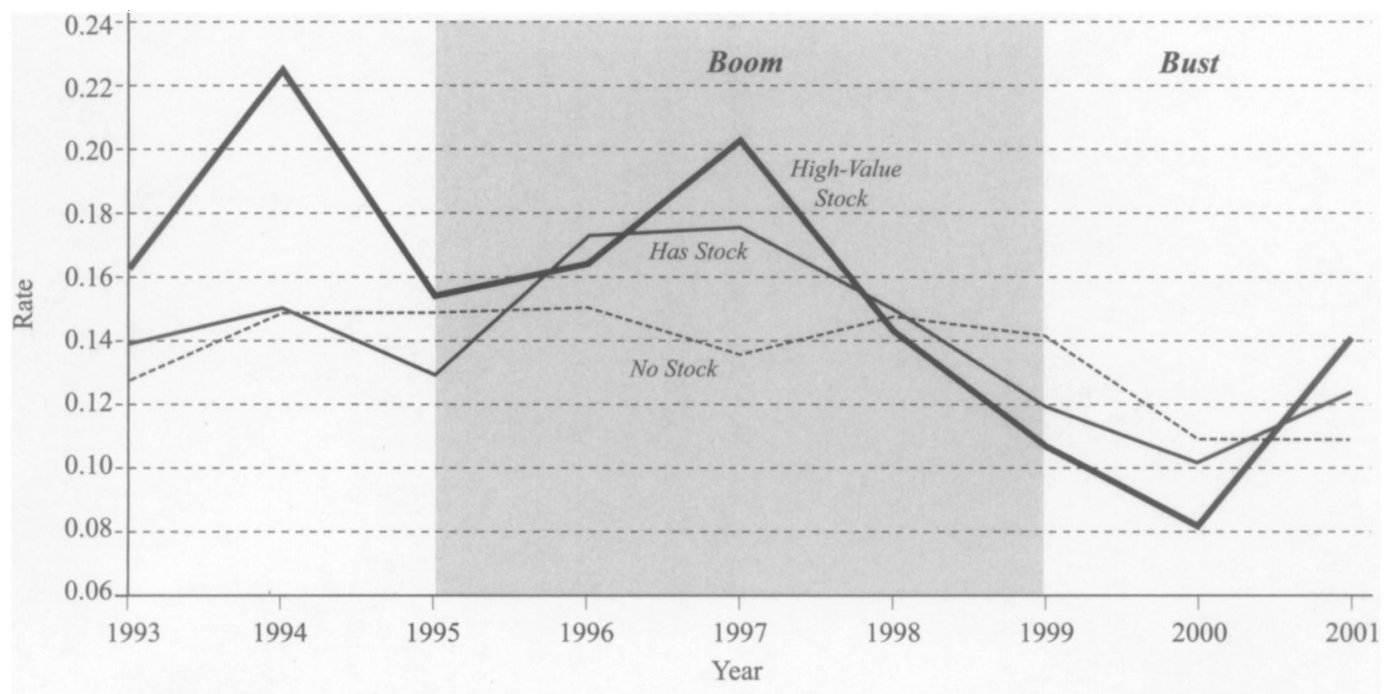

Notes: Rates reflect retirement behavior adjusted for variation in the unemployment rate and the exact age composition of 60 to 65 year olds. The estimates assume an unemployment rate of $5 \%$ and are measured at the average retirement hazard between age 60 and 65 .

\section{Regression Results}

\section{Retirement}

Before describing the regression results in detail, we provide two graphical examples that preview those results. Figure 3 uses HRS data and distinguishes individuals with no DC plan or IRA, those with a DC plan or IRA, and those with DC and IRA combined balances in excess of $\$ 50,000$. The figure compares cyclically adjusted retirement behavior over time for workers between the

\footnotetext{
depressed" (the opposite of irrationally exuberantthanks to Dan Hamermesh for the terminology), and would choose to work longer despite the small impact on their retirement income in response to the falling stock market. Although we have no way to disprove this hypothesis, one would presume that the impact would be greater for workers with more stock market exposure even in the face of irrational depression. We take up the differential responsiveness in the following section.
}

ages of 60 and 65 . All experienced identical drops in retirement between 1999 and 2000. Individuals with high-value DC and IRA balances did have much higher retirement rates in 1996-98, but that differential disappeared in 1999. Moreover, it is not clear whether this was a response to the boom or simply a difference in the underlying propensity to retire, as the retirement rate was higher for those with a pension or IRA in the pre-boom period as well.

Figure 4 provides another example, using HRS data and comparing retirement rates by an even more direct measure of stock market exposure, whether the household owned individual stocks or stock mutual funds. The expected larger response to the stock market drop by those exposed to the market again fails to materialize-in fact, the drop in the retirement rate between 1999 and 2000 was larger for individuals with no stock than for individuals with any stock or with stock holdings in excess of $\$ 50,000$. The high-value stock 


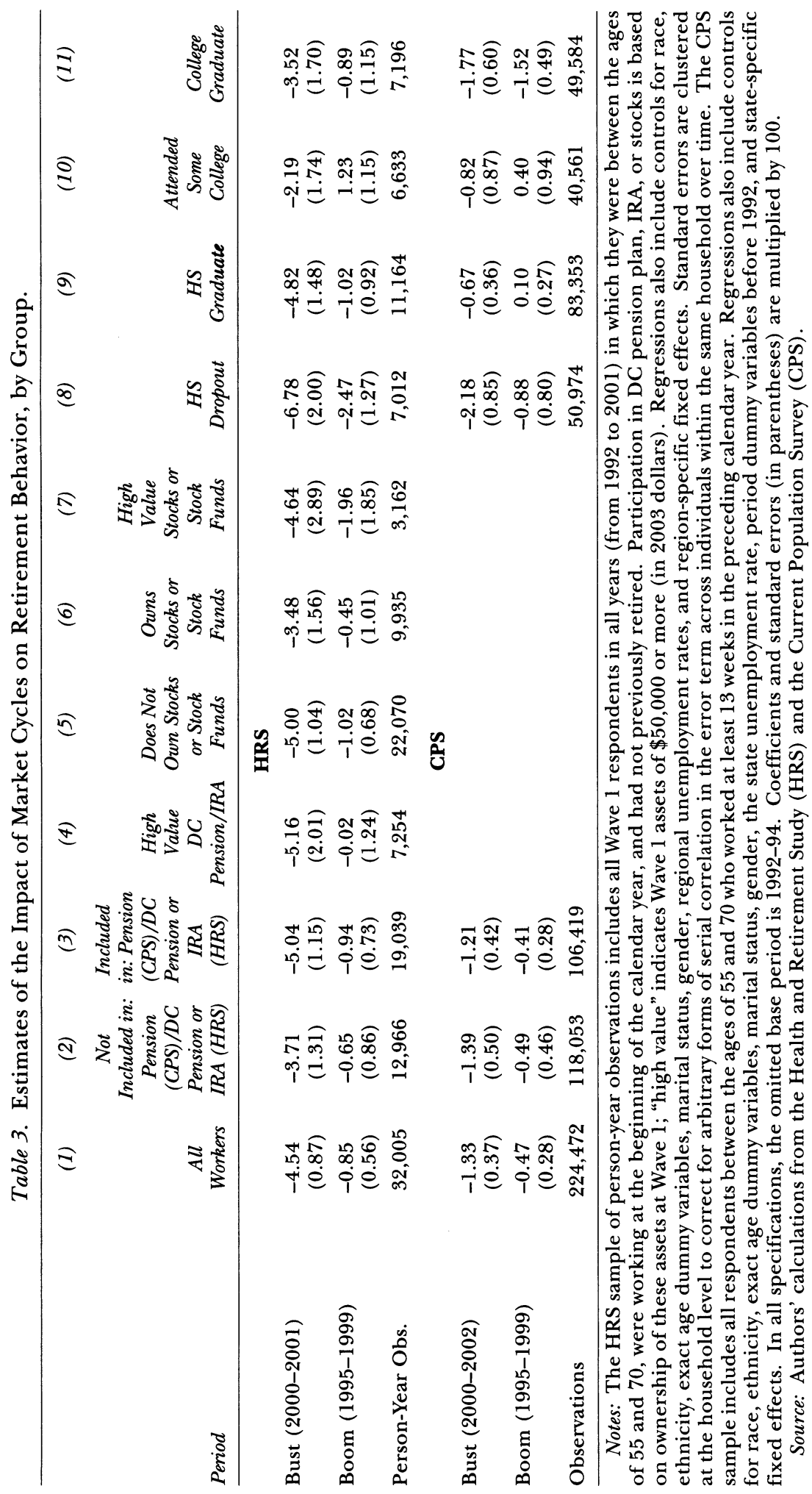


group had a higher retirement rate in 1997 during the boom, but not during the rest of that period, and also had a higher rate in 1994 before the boom. Overall, the figures provide no support for the hypothesis that workers who were more likely to be affected by the drop in the stock market in 2000 reduced their retirement relative to other workers and inconsistent support at best for the hypothesis that these workers increased their retirement rate in the boom period of the late 1990s. ${ }^{23}$

The regression analysis formalizes the results in these figures in a framework that also controls for demographic characteristics, the unemployment rate, and state- or region-specific fixed effects. Table 3 reports the linear probability model estimates of equation (1) for the workers in the HRS (top panel of the table) and the CPS (bottom panel).$^{24}$ The first column largely presents a parameterized version of the patterns presented in Figure 1, where years have been aggregated into periods, demographic controls are included, and we use a sample of workers who are 55 to 70 rather than 60 to 65 to improve precision. Consistent with that figure, we see that retirement rates fell during the bust period (20002002) relative to the baseline (1992-94), but did not rise during the boom period (1995-99).

More interesting for our purposes is the comparison of the boom and bust coefficients across columns in the rest of the table. As in the figures, we examine whether

\footnotetext{
${ }^{23} \mathrm{We}$ also have conducted analogous exercises comparing workers with different levels of educational attainment in both the CPS and the HRS and comparing workers by pension status in the CPS. In no case do we see any support for the hypothesis that the groups more likely to be exposed to stock market fluctuations were more (less) likely to retire in the boom (bust).

${ }^{24}$ In the CPS regressions, standard errors are clustered at the year level to correct for arbitrary forms of serial correlation in the error term across individuals within the same survey year. In all HRS regressions, standard errors are clustered at the household level to correct for arbitrary forms of serial correlation in the error term across individuals within the same household over time.
}

the retirement rate fell by more in the bust period and whether it rose by more (or fell by less) relative to the omitted period for groups with greater exposure to the stock market. We find no evidence to support this hypothesis. For example, in the HRS the retirement rate in the bust period was 5.0 percentage points lower than in the early 1990s for those who did not own stocks, compared to 3.5 percentage points lower for those who did own stocks and 4.6 percentage points lower for the subset of those with greater than $\$ 50,000$ in stock assets. These estimates are not statistically significantly different from each other. In the case of a DC plan or IRA, the retirement rate was 3.7 percentage points lower for individuals without such assets compared to 5.2 percentage points lower for individuals with $\$ 50,000$ or more in such assets, but the difference is not statistically significant. The remainder of the table provides similar results by pension status in the CPS and by education status in both datasets. Overall, we find no evidence in either the CPS or HRS regressions that workers with greater exposure to the stock market reduced their retirement rate during the bust period relative to other workers. The results provided in this table also do not support the notion that those with greater exposure were more likely to retire when the market was doing well. ${ }^{25}$

\footnotetext{
${ }^{25}$ Our results can be easily reconciled with Sevak (2001), who found statistically significant effects of unanticipated stock market gains on retirement but projected that the gains experienced in the late 1990s had only a very minor effect on aggregate retirement behavior. As she noted, "Although the data find quite large wealth effects, because many individuals have negligible wealth gains over the period, the aggregate effect is quite small." Our results are somewhat less consistent with Coronado and Perozek (2003), who found that being a stockholder was associated with retiring earlier than expected in the late 1990s, relative to non-stockholders. Yet Kezdi and Sevak (2004) found that stockholders also retired earlier than nonstockholders in the 2000-2002 bust period, suggesting that differences in behavior could in part reflect unobserved heterogeneity between stockholders and non-stockholders.
} 


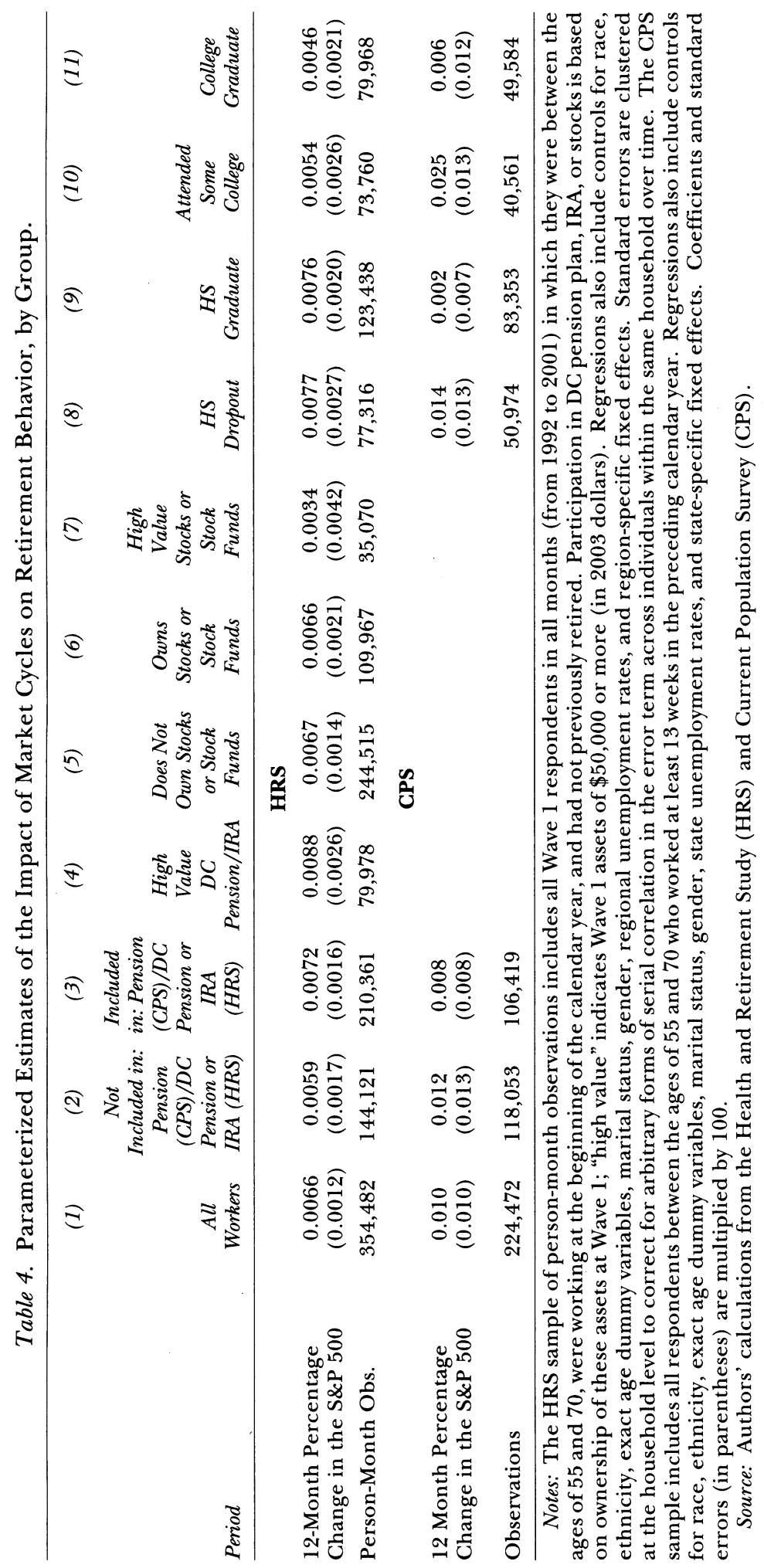


Table 4 presents the linear probability model estimates of equation (2), which quantifies the relationship between the stock market and retirement. The key explanatory variable in this specification is the percentage change in the S\&P 500 Index over the previous twelve months. ${ }^{26}$ The coefficient on this variable is expected to be positive, as workers should be more likely to retire when the stock market rises due to wealth effects. In the HRS, the availability of month of retirement in the data allows the analysis to be conducted using personmonth observations. Therefore, estimates based on the HRS should be smaller than those from the CPS, since we are comparing the effect of a given change in the S\&P 500 Index on monthly versus annual retirement rates. ${ }^{27}$ In the HRS, a $10 \%$ rise in the $\mathrm{S} \& \mathrm{P}$ is associated with a 0.066 increase in the monthly retirement rate for all workers; the effect is statistically significant. In the full CPS sample, a $10 \%$ rise in the S\&P 500 is associated with a 0.10 percentage point increase in the annual retirement rate, although the effect is not statistically significant.

As in the earlier tables, our primary interest is in testing whether this effect was larger for workers who were more likely to be exposed to the stock market, and once again, the results do not support this hypothesis. Comparing this coefficient across groups, there is no evidence that groups with greater stock market exposure were more responsive to change in the S\&P. For example, in the HRS a $10 \%$ rise in the S\&P is associated with a 0.059 percentage point increase in the monthly retirement rate for workers with no DC plan or IRA, compared to 0.072 for all workers with such assets and 0.088 for workers with balances of $\$ 50,000$

\footnotetext{
${ }^{26}$ In the HRS, results are qualitatively similar when the key variable is defined as the percentage change in the S\&P Index over the previous two or three years, though statistically insignificant when defined as the percentage change over the previous five years.

${ }^{27}$ When the HRS analysis is conducted using a person-year sample, the magnitude of the coefficients is similar to those in the CPS.
}

or more in such assets, but these differences are small and not statistically significant. The results are even more striking in the case of stock ownership-the S\&P coefficients for workers with and without stock are identical, and the coefficient for those with stock assets of $\$ 50,000$ or more is half as large as that for workers with no stock, although the difference is not statistically significant. Patterns by educational status in both data sources and by pension status in the CPS similarly do not support the hypothesis that the sensitivity of retirement behavior to market returns increases with stock market exposure. ${ }^{28}$

\section{Labor Force Re-Entry}

Finally, we examine the effect of market fluctuations on labor force re-entry. The effect is expected to be the opposite of that predicted for retirement: workers should be less likely to re-enter during a stock market boom and more likely to do so during a bust, and the effect should again be larger for those with greater stock market exposure. Here we report the results of linear probability models of labor force reentry comparable to those reported in Table 4 , where the key explanatory variable in this specification is the percentage change in the S\&P 500 Index over the previous twelve months. ${ }^{29}$ For reference, the aver-

\footnotetext{
${ }^{28}$ In order to test the sensitivity of our results to the choice of retirement definition, we have replicated Table 4 using two other dependent variables, retirement based on self-reported retirement status (transitioning from being not retired to either partly or completely retired) and the change in hours (for those working at the previous wave). In both cases, we fail to find statistically significant differences across stock proxy groups.

${ }^{29} \mathrm{An}$ earlier version of this paper (Coile and Levine 2004) reported the results of reduced form specifications much like those reported in Table 3 . The results reported there do not support the hypothesis that there were higher (lower) rates of labor force re-entry during the bust (boom) for those groups with greater stock market exposure. In the CPS sample, we no longer report results separately for those with and without a pension, because only a small number of respondents in the labor force re-entry sample reported this information.
} 


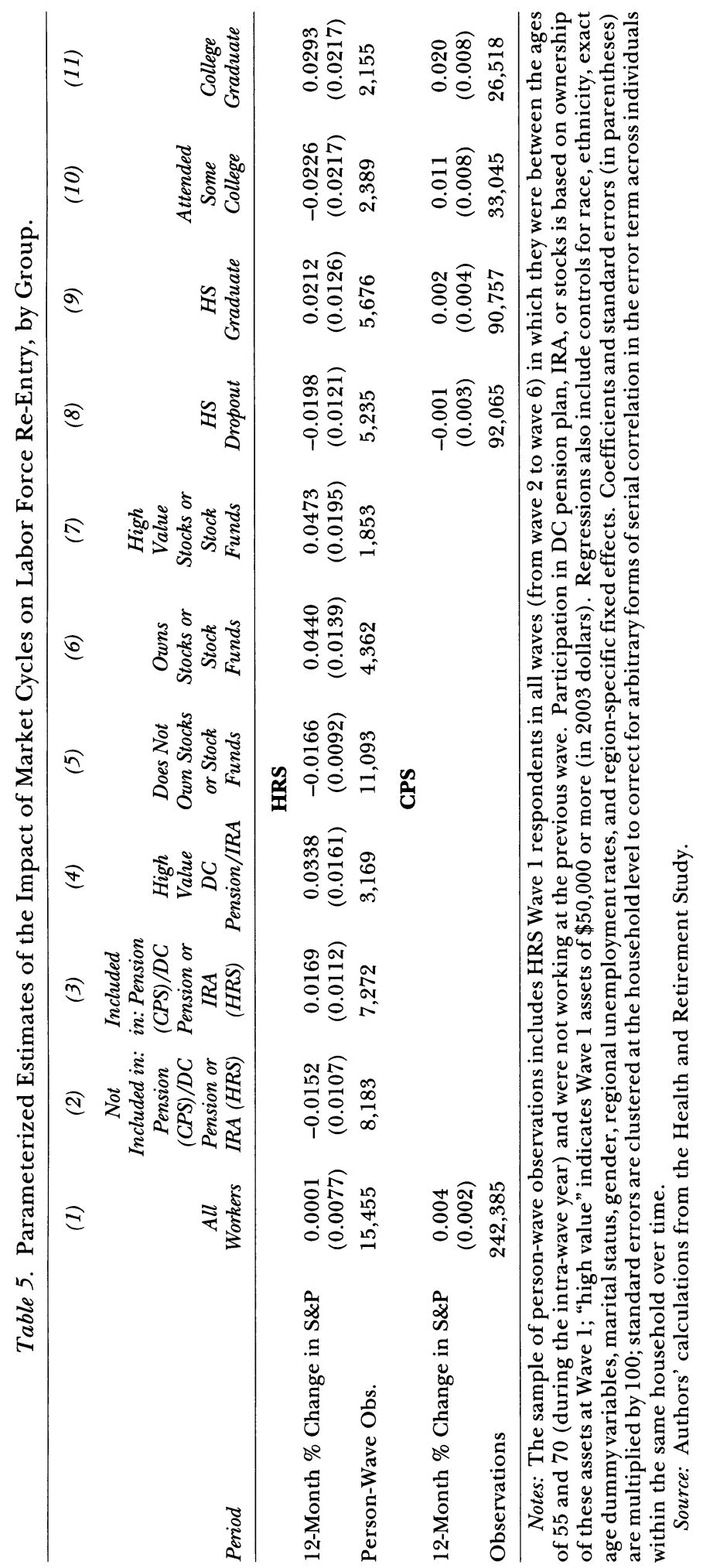


age rate of re-entry is $2.5 \%$ per year in the CPS and $8.0 \%$ per wave in the HRS. ${ }^{30}$

Table 5 presents the results of this analysis. ${ }^{31}$ We expect workers with greater exposure to have been relatively less likely to reenter in response to an increase in the S\&P 500 Index. In fact, the opposite pattern is evident in both the HRS and CPS, and at least in the case of stock ownership, the differences are statistically significant. Thus, we are unable to find any evidence that retirees re-entered the labor force at a faster pace when the stock market dropped.

\section{Extensions}

We conduct a number of specification checks to assess the robustness of these results, focusing our discussion on models of retirement for simplicity. First, we consider the argument that there is heterogeneity in workers' responsiveness to stock market fluctuations conditional on the level of stock holdings and that those workers who are most responsive retired during the boom and thus were not in the sample to delay retirement during the bust. This strikes us as a plausible hypothesis, but if it were correct, we would expect to see a bigger increase in retirement in the boom period for groups with greater market exposure (as some of the workers in these groups would be the responsive ones who would choose to retire) than for groups with less market exposure. We do not observe this pattern.

Second, we explore the hypothesis that younger workers were more responsive to

\footnotetext{
${ }^{30} \mathrm{The}$ discrepancy partly reflects the difference in survey periods, with two years between HRS waves versus one year for the CPS. Others have noted the relatively high rate of labor force re-entry in the HRS. For example, Bruce, Holtz-Eakin, and Quinn (2000) found that $15 \%$ of those who were out of the labor force in 1992 were employed or self-employed in 1996.

${ }^{31}$ In HRS analysis, the percentage change in the S\&P 500 is the contemporaneous change across waves (for example, the change from January 2000 to January 2002 is used for labor force transitions between waves 5 and 6 ).
}

stock market fluctuations, as might have been the case if their decisions were based more on finances while older workers' decisions were based more on health status or social norms. To do so, we re-estimate the models separately for workers aged 55-59 and 60-65. In both subsamples the pattern of boom and bust coefficients is inconsistent with that predicted if the stock market had had an impact on retirement behavior.

Third, we explore the effect of the market on a worker's decision to work full-time or part-time. To do so, we re-estimate the model limiting the sample to those working full-time (35 or more hours per week) and define the dependent variable in one specification as moving to part-time work and in a second specification as either moving to part-time work or exiting the labor force completely. We find no evidence of a greater response to market fluctuations among those with greater market exposure in either of these alternative specifications.

Finally, we perform two other checks. First, as labor supply is more difficult to measure for the self-employed than for other workers, we drop self-employed workers from our analysis. The results are very similar to those found earlier. Second, to account for the possibility that some households experienced large increases in their housing wealth at the same time their stock portfolios fell, we include the change in real house value in the regression. We find that its coefficient is statistically insignificant and the coefficients on the boom and bust dummies are unaffected by its inclusion. Overall, none of these extensions changes the nature of our earlier findings.

\section{Conclusions}

This paper has explored the impact of stock market fluctuations on retirement behavior. We take advantage of a unique double experiment that compares labor force exits for groups that were more and less exposed to those fluctuations to determine whether differences emerged during the recent boom and then reversed in the subsequent bust. Our focus is exclusively on the ability of the market to generate 
changes in aggregate retirement behavior, and not on the estimation of wealth effects for individuals. These two features distinguish our work from that preceding it.

The results of our analysis provide little support for an impact of market fluctuations on retirement or labor force re-entry. This conclusion is based on the relatively small number of households with sizeable stock holdings, the magnitude of their retirement response that would be required to generate the types of retirement patterns observed recently, and our inability to find any evidence that population subgroups who should have been more responsive to market fluctuations were more responsive.

Our results do not necessarily contradict previous studies that have found wealth effects associated with changes in the stock market or other unanticipated wealth shocks. On the contrary, it is almost certainly true that some individuals experienced large drops in wealth because of the market bust and retired later as a result. But we suspect that this is a fairly narrow segment of the population. As we illustrate in our descriptive analysis, most workers have few if any stock assets; at the other end of the distribution, some workers may have sufficient wealth holdings that even a sizeable financial loss would not alter their retirement behavior. There is a group of workers in the middle whose retirement decisions are affected by stock market fluctuations, but it is a sufficiently small group that we are unable to identify them in conventional data sets. Thus it seems unlikely that even a substantial labor supply response by this group could be driving large changes in aggregate labor market trends.

Despite our findings, stock market fluctuations are likely to have broader implications for individuals' behavior and wellbeing. Recent retirees, workers of nearretirement age, and workers further from retirement all may respond in any number of ways, such as changing their level of consumption, altering savings and investment activities, updating expectations about leaving a bequest, or adjusting longer-term retirement plans or spousal labor supply (for younger workers). Indeed, there is some evidence to suggest that consumption is sensitive to market fluctuations. Maki and Palumbo (2001) found that households increased consumption by 3.5 to 5 cents per year for each dollar of stock market wealth generated during the market boom of the 1990s, and Kezdi and Sevak (2004) obtained similar results for the bust period, with a somewhat larger response by retirees. We conclude that changes in wealth brought about by market fluctuations may be reflected to a much greater extent in changes in consumption and possibly other behaviors than in changes in labor supply of near-retirement-age workers or recent retirees. 


\section{REFERENCES}

Allison, Paul D. 1984. Event History Analysis: Regression for Longitudinal Event Data. London: Sage.

Bruce, Donald, Douglas Holtz-Eakin, and Joseph Quinn. 2000. "Self-Employment and Labor Market Transitions at Older Ages." Center for Retirement Research at Boston College, Working Paper 200013.

Burtless, Gary, and Joseph F. Quinn. 2002. Is Working Longer the Answer for an Aging Work Force? Center for Retirement Research at Boston College. Issue Brief No. 11.

Cheng, Ing-Haw, and Eric French. 2000. "The Effect of the Run-Up in the Stock Market on Labor Supply." Economic Perspectives, Fourth Quarter, pp. 4865.

Coile, Courtney, Peter Diamond, Jonathan Gruber, and Alain Jousten. 2002. "Delays in Claiming Social Security Benefits." Journal of Public Economics, Vol. 84, No. 3, pp. 357-85.

Coile, Courtney C., and Phillip B. Levine. 2004. "Bulls, Bears, and Retirement Behavior." National Bureau of Economic Research, Working Paper 10779.

Coronado, Julia, and Maria Perozek. 2003. "Wealth Effects and the Consumption of Leisure: Retirement Decisions During the Stock Market Boom of the 1990s." Board of Governors of the Federal Reserve System, Finance and Economics Discussion Series No. 2003-20.

Engen, Eric, William G. Gale, and Cori E. Uccello. 2004. "Effects of Stock Market Fluctuations on the Adequacy of Retirement Wealth Accumulation." Center for Retirement Research at Boston College, Working Paper 2004-16.

Eschtruth, Andrew D., and Jonathan Gemus. 2002. Are Older Workers Responding to the Bear Market? Center for Retirement Research at Boston College, Just the Facts on Retirement Issues No. 5.

Friedberg, Leora, and Anthony Webb. 2003. "Retirement and the Evolution of Pension Structure." National Bureau of Economic Research, Working Paper 9999.

Gustman, Alan L., and Thomas L. Steinmeier. 2002. "Retirement and the Stock Market Bubble." National Bureau of Economic Research, Working Paper 9404.

Holtz-Eakin, Douglas, David Joulfaian, and Harvey S. Rosen. 1993. "The Carnegie Conjecture: Some Empirical Evidence." Quarterly Journal of Economics, Vol. 102, No. 2 (May), pp. 413-35.
Hurd, Michael, and Monika Reti. 2001. "The Effects of Large Capital Gains on Work and Consumption: Evidence from Four Waves of the HRS." RAND Labor and Population Program, Working Paper Series 03-14.

Hurd, Michael, Monika Reti, and Susann Rohwedder. 2005. "The Effect of Large Capital Gains or Losses on Retirement." Unpublished paper, Rand Corporation.

Imbens, Guido W., Donald B. Rubin, and Bruce I. Sacerdote. 2001. "Estimating the Effect of Unearned Income on Labor Earnings, Savings, and Consumption: Evidence from a Survey of Lottery Players." American Economic Review, Vol. 91, No. 4 (September), pp. 778-94.

Joulfaian, David, and Mark Wilhelm. 1994. "Inheritance and Labor Supply." Journal of Human Resources, Vol. 29, No. 4 (Fall), pp. 1205-34.

Kennickell, Arthur B., Martha Starr-McCluer, and Brian J. Surette. 2000. "Recent Changes in U.S. Family Finances: Results from the 1998 Survey of Consumer Finances." Federal Reserve Bulletin.

Kezdi, Gabor, and Purvi Sevak. 2004. "Economic Adjustment of Recent Retirees to Adverse Wealth Shocks." Michigan Retirement Research Center, Working Paper 2004-75.

Krueger, Alan B., and Jorn-Steffen Pischke. 1992. "The Effect of Social Security on Labor Supply: A Cohort Analysis of the Notch Generation." Journal of Labor Economics, Vol. 10, No. 4 (October), pp. 412-37.

Maki, Dean M., and Michael G. Palumbo. 2001. "Disentangling the Wealth Effect: A Cohort Analysis of Household Saving in the 1990s." Federal Reserve Finance and Economics Discussion Series, Working Paper 2001-21.

Poterba, James M. 2001. "The Rise of the "Equity Culture': U.S. Stockownership Patterns, 1989-1998." Unpublished manuscript, MIT.

Sevak, Purvi. 2001. "Wealth Shocks and Retirement Timing: Evidence from the Nineties." Michigan Retirement Research Center, Working Paper WP00D1.

U.S. Census Bureau. 1999. Current Population Reports, P60-206, Money Income in the United States, 1998. Washington, D.C.: U.S. Government Printing Office.

U.S. Department of Labor, Bureau of Labor Statistics. 2004. Consumer Expenditures in 2002 (Report 974). Washington, D.C.: U.S. Department of Labor. 